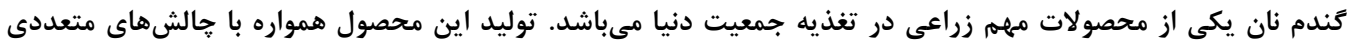

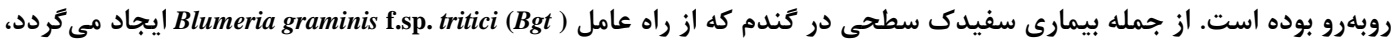

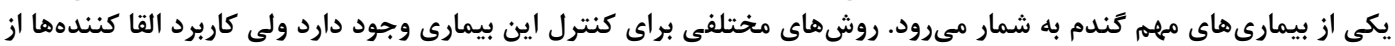

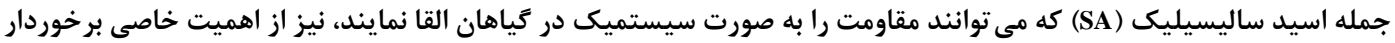
است. در اين تحقيق به منظيد اليسيك (SA

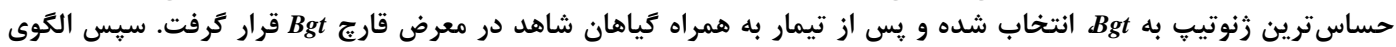

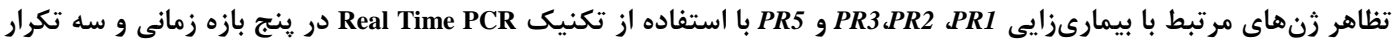

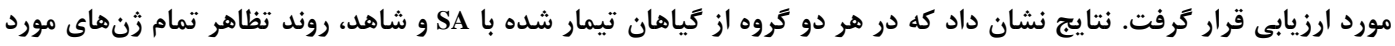

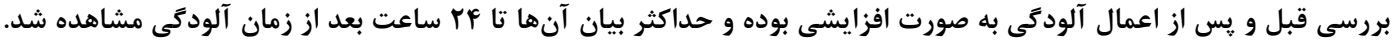

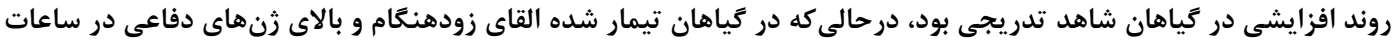

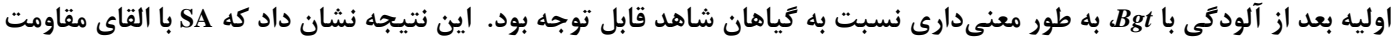

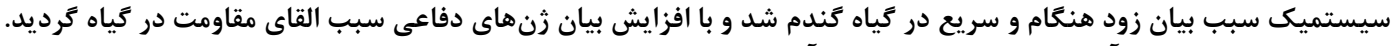

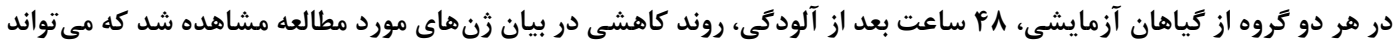

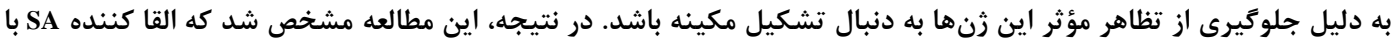

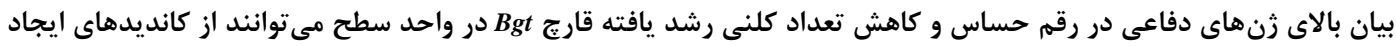

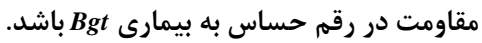

وازههاى كليدى: كَندم، اسيد سالسيليك، بيان زن، القاى مقاومت

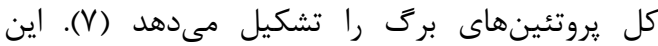

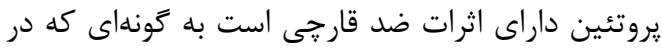
شرايط آزمايشگاهى، اسيور و كاهش طول لوله تندشى قارئ Phythophthora infestans

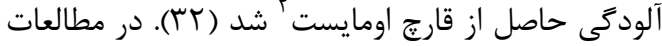

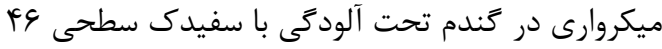

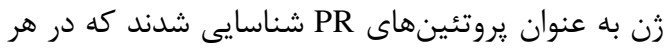

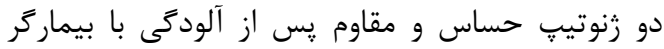

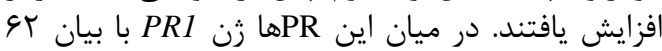

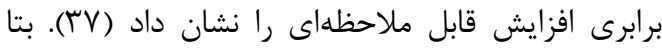

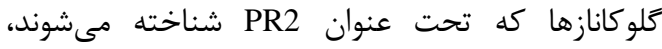

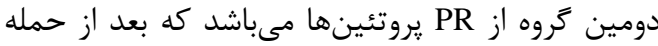

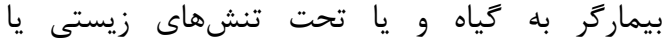

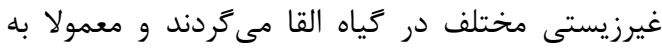
صورت سينرزيكى با آنزيم كيتيناز عمل مئى كنياه المند (YV)

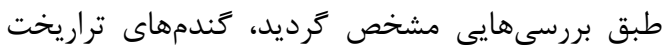

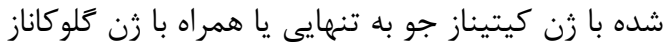

مقدمه

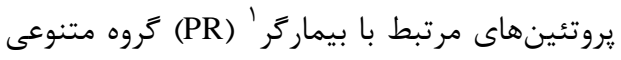

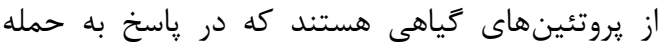

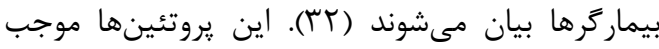

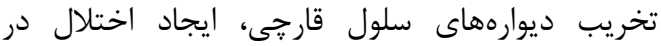

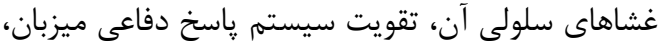

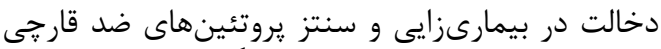

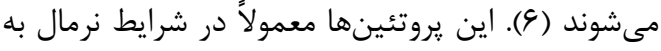

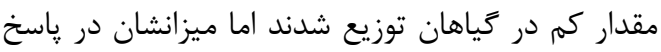

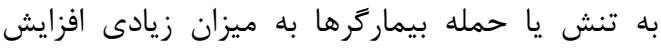

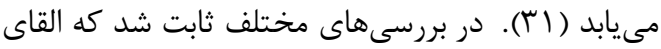

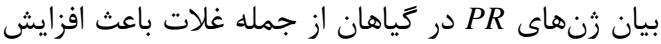

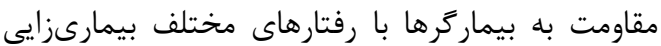

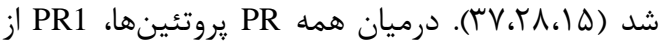

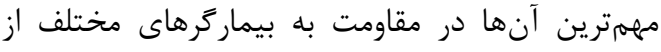

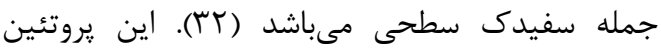

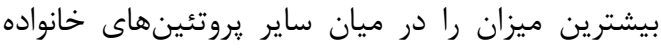

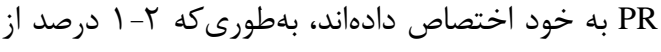


در بافتها به صورت سيستميك و موضعى منجر

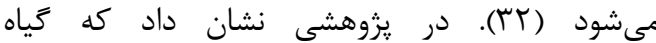

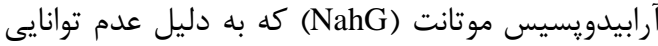

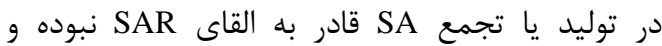
حساسيت بالايى را به قارج

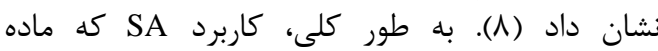
علامتدهنده است سبب تغييرات اكسايشى سلول، فران فعال

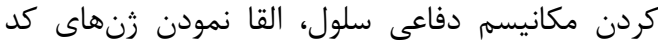

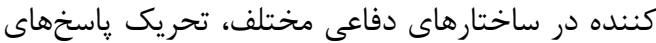

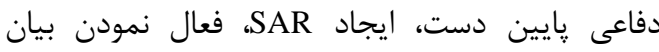

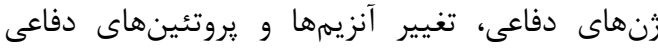

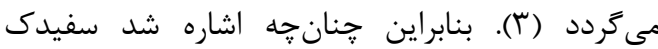

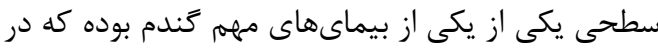

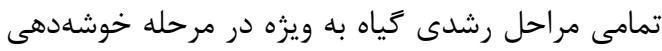

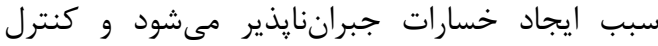

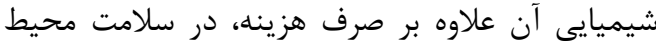

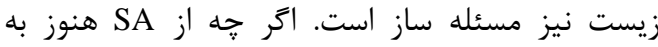

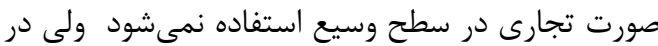

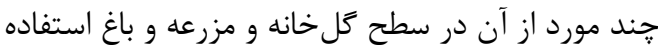

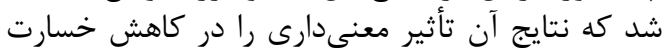

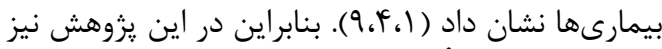

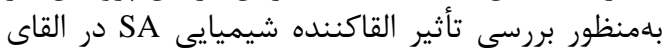

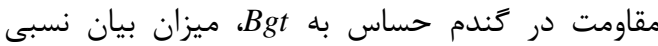

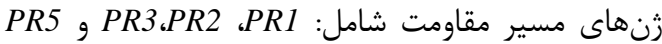

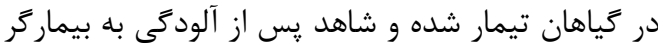

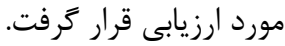

\section{مواد و روشها مواد تياهى و نحوه تهيه و نكَهدارى قارج سفيدك سطحى

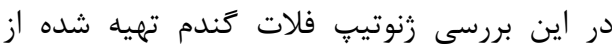

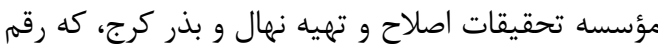

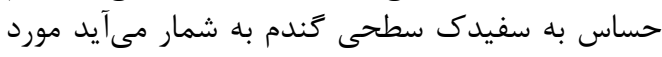

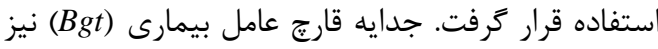

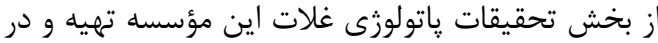

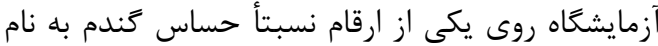

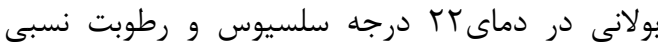 • •}

( $(Y \cdot)$

تيمار كياهان حساس به قارج Bgt با اسيد سالسيليك

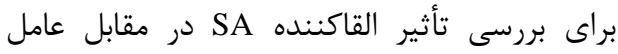

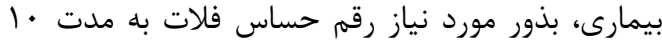

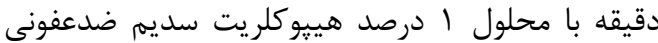

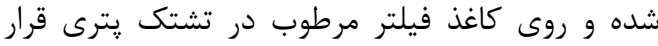

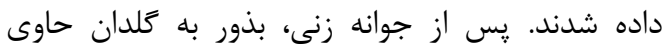

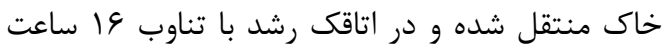

جو مقاومت بالايى را نسبت به گياهان كنترل به آلودَّى

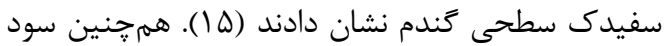

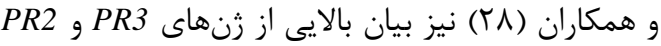

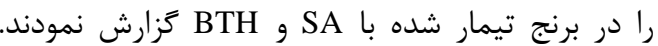

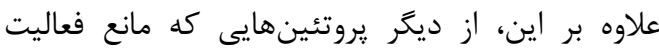

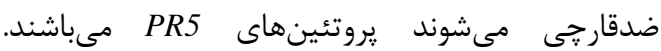

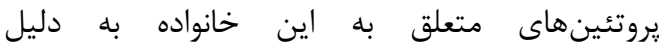

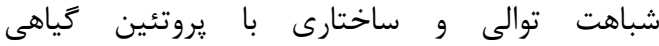
تاماتي تاماتين ' (TLPs) هم معروف هستند (1) (1). يروتئين

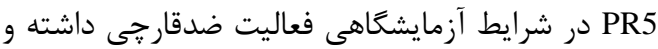

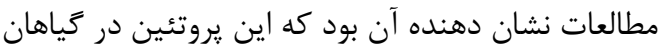

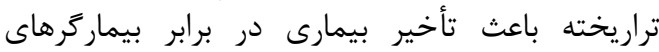

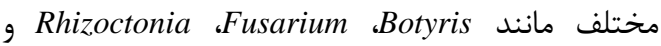
Sclerotinia

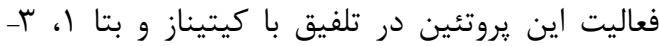

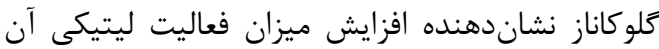

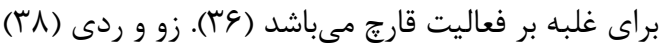

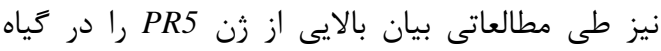

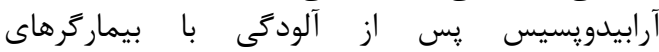

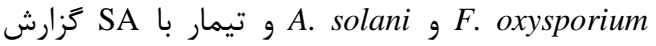

بيمارى سفيدى سطحى گندم كه بهوسيله يك قارج

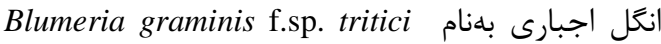
ايجاد مى (Bgt)

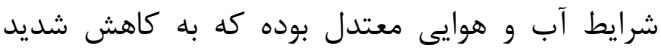

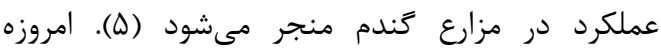

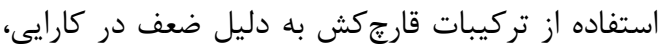

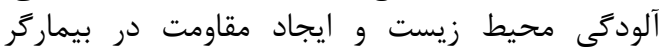

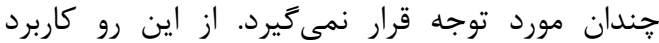
تركيبات طبيعى و نيز استفاده از عوامل القاء كنيندهنهاى مقاومت مثل تركيبات شيميايى (اسيد سالسيليك) و و

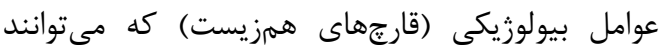

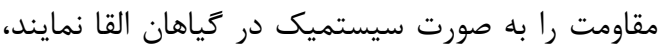

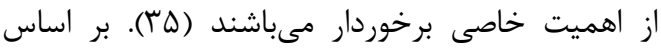

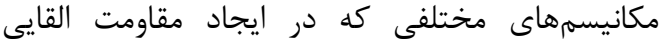

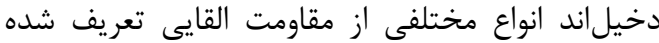

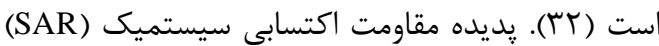
كه نياز به تجمع مولكولهاى اسيد سالسيليك (SA)

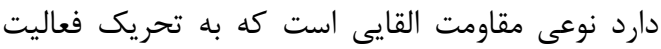

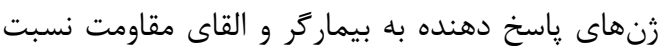

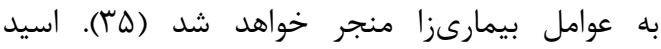

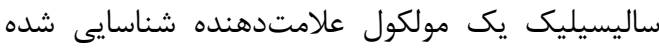
است كه مىتواند نقش محورى در القاى مقاومت گئياهان

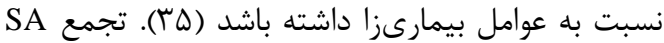

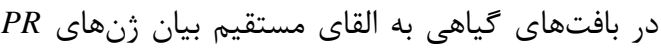


$r$. بررسى الكوى بيان زنهاى مرتبط با بيمارىزايى در القاى مقاومت به بيمارى سفيدى سطحى در رقم حساس كندم.

اندازهيرى الكَوى بيان زنهاى مورد مطالعه بررسى بيان زن (qRT-PCR) با استفاده از دستيان و C1000 Thermal Cycler (BioRad) Maxima SYBR Green/ROX qPCR Master Mix

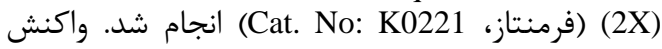

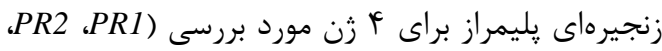

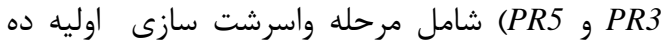

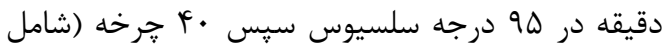

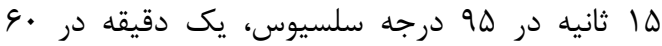

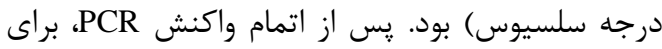

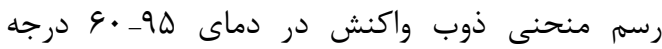

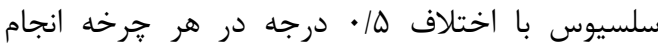

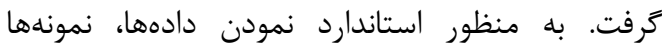
أبوسيله زن خانهاردار

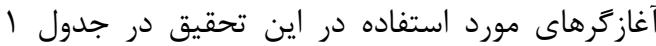

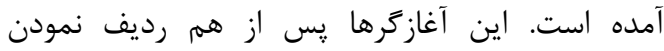

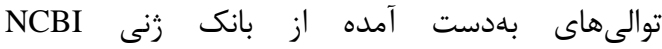
(http://www.ncbi.nlm.nih.gov/) OligoExplorer V1.4 , BioEdit 7.0.9.0

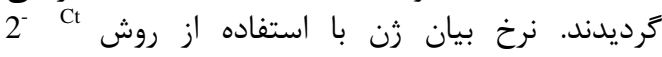

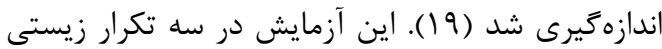

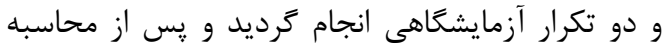

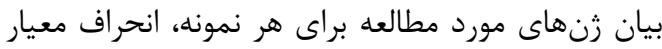

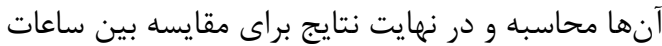

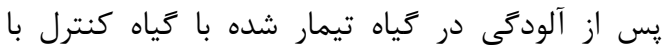
استفاده از آزمون t آناليز شدند.

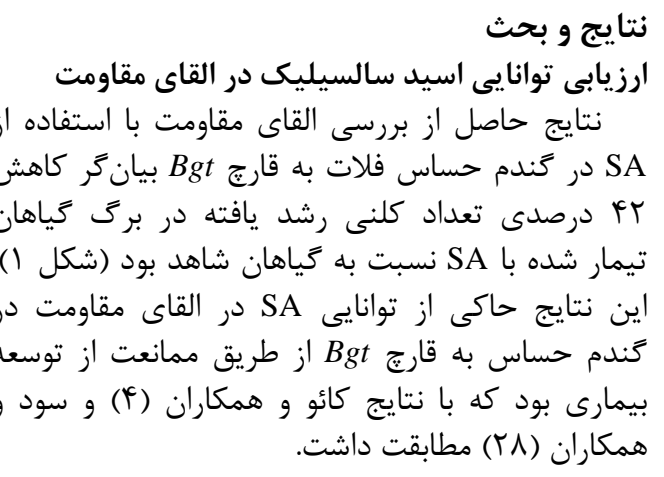

روشنايى با دماى Tr ب درجه سلسيوس و هشت ساعت

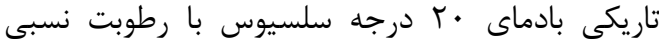

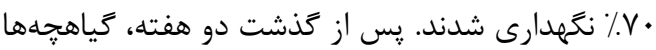

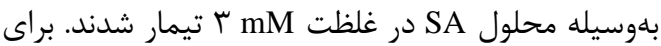

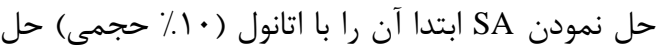

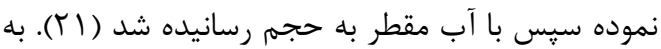

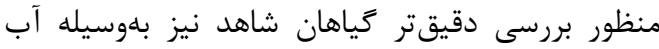

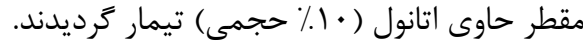

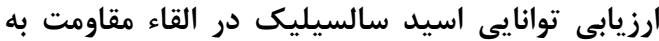
سفيدى سطحى توانى استي بلمنظور بررسى توانايى SA در القاى مقاومت در در

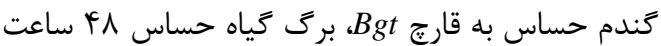

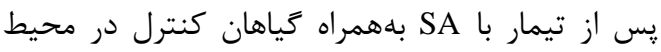

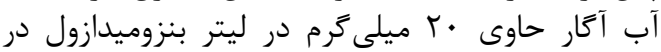

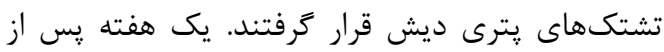

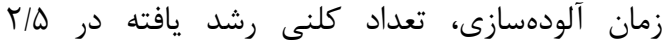

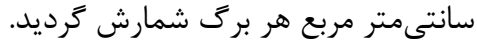

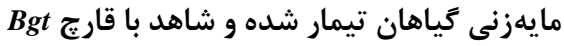

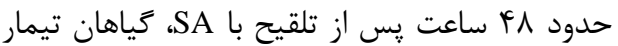

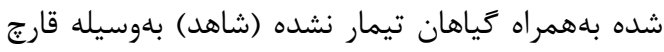

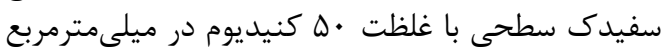

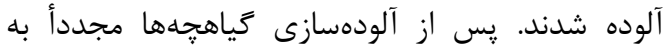

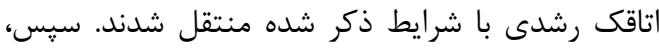

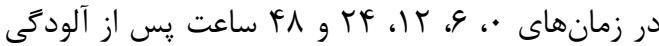

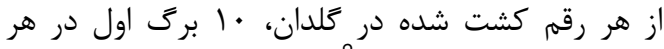

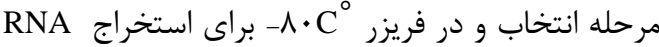

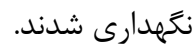

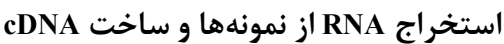

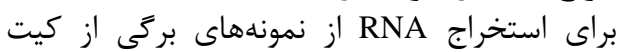
(Cat, No: RN7713C) شركت سينازن RNX-plus

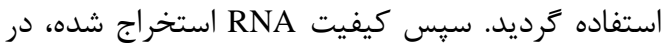

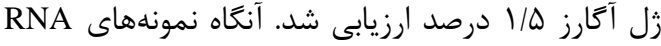

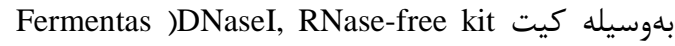

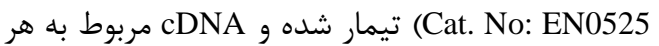

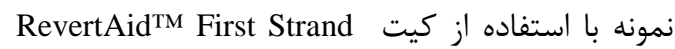

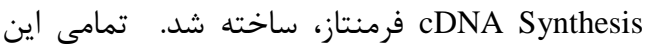
مراحل طبق دستورالعمل هر كيت انجام كرفت. 
جدول ا- ليست آغازگر هاى مورد استفاده به همراه محصول نهايى

\begin{tabular}{|c|c|c|}
\hline Genes & Sequence Primer & Product \\
\hline TaActin & $\begin{array}{l}\text { F: GGA AAA GTG CAG AGA GAC ACG } \\
\text { R: TAC AGT GTC TGG ATC GGT GGT }\end{array}$ & 10. \\
\hline$T a P R I$ & $\begin{array}{l}\text { F: ACT ACG ACT ACG GGT CCA ACA } \\
\text { R: TCG TAG TTG CAG GTG ATG AAG }\end{array}$ & lQF \\
\hline$T a P R 2$ & $\begin{array}{l}\text { F: AGC AGA ACT GGG GAC TCT TCT } \\
\text { R: CAC ATA CGT ACC GCA TAC ACG }\end{array}$ & 10 \\
\hline$T a P R 3$ & $\begin{array}{l}\text { F: CCC TAC ACA TGG GGC TAC TG } \\
\text { R: CCT GCC CGT AGT TGT AGT TGT }\end{array}$ & $1 F \Delta$ \\
\hline Ta PR5 & $\begin{array}{l}\text { F: CAG GAC TTC TAC GAC ATC TCG } \\
\text { R: TCT GGT AGT TAT TAT TGC CAC TGC }\end{array}$ & ler \\
\hline
\end{tabular}

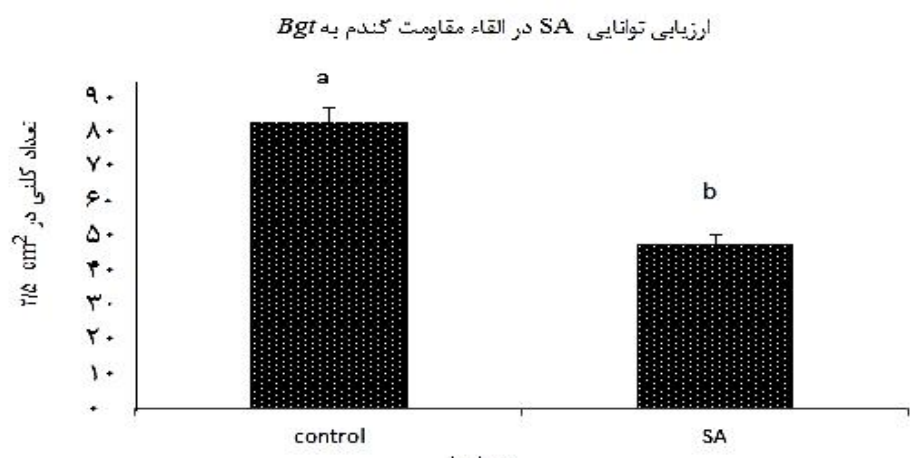

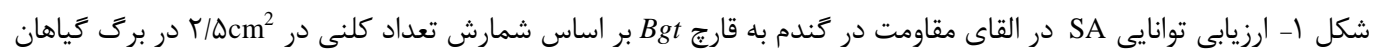

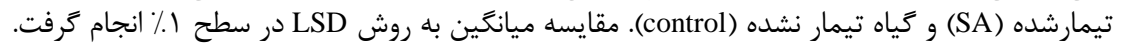

رونوشت حاكى از آن بود كه ميزان بيان در كياهان

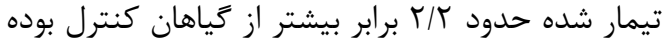

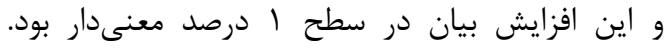

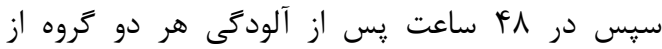

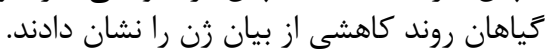

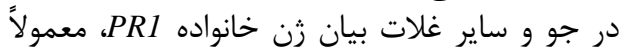

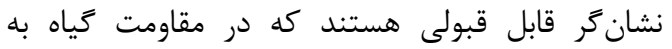

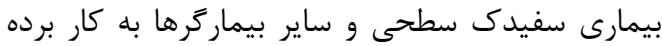

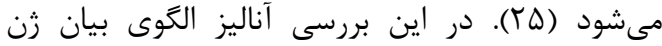

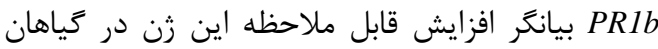

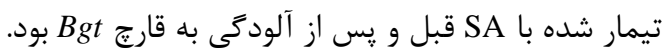

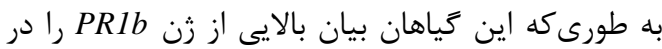

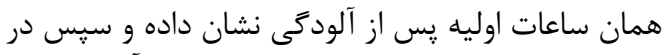

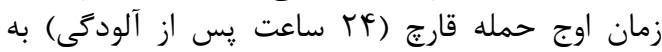

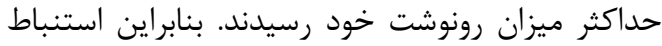

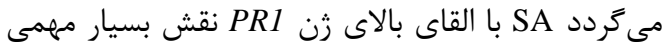

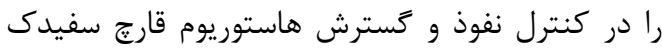

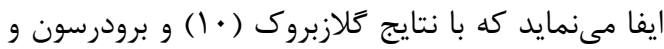

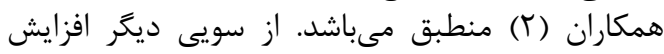

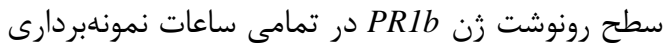

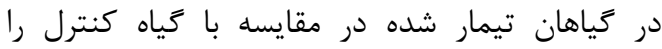

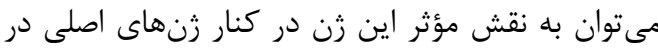

بررسى بيان زنهاى PR توسط RT-PCR كمى وضعيت

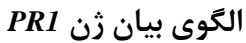

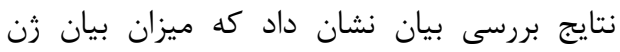

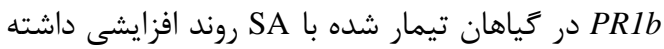

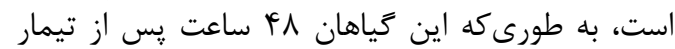

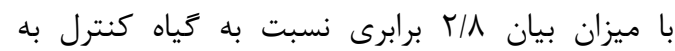

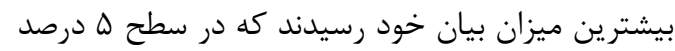

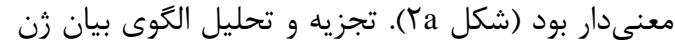

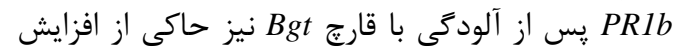

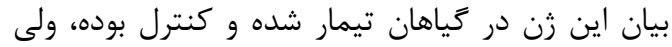

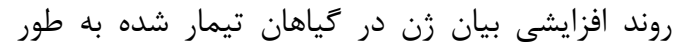

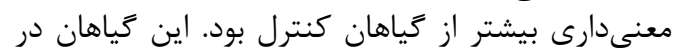

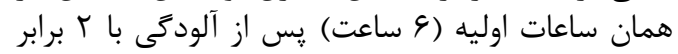

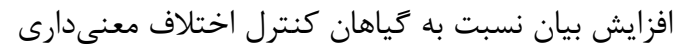

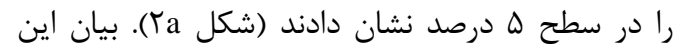

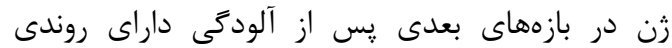

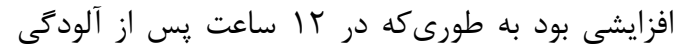

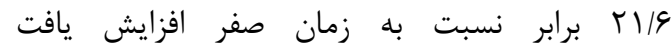

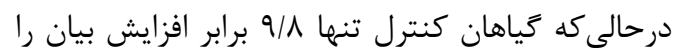

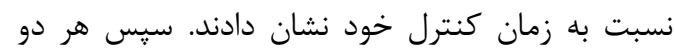

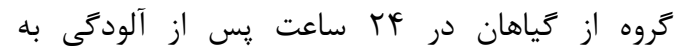
بيشترين ميزان بيان خود رسيدند. ولى مقايسه ميزان الن الودي 
مىشود كه يس از درك آن محركى است كه سبب فعال

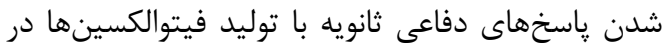

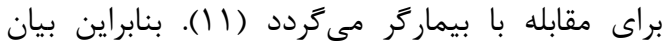

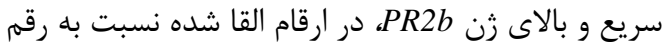

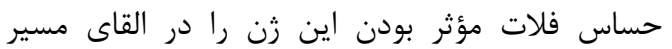

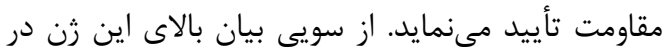

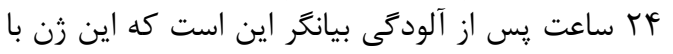

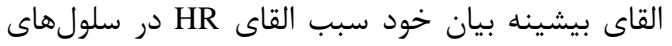

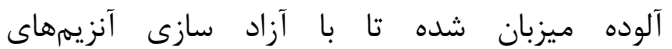

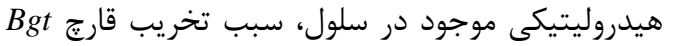

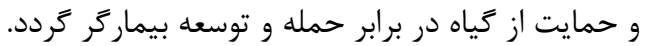

وضعيت الكوى بيان زن كيتيناز (PR3)

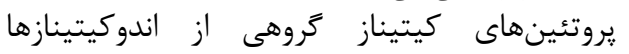

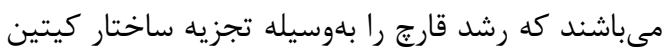

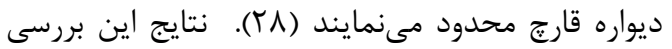

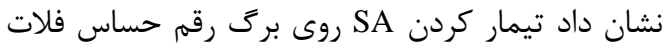

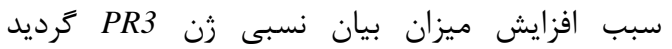

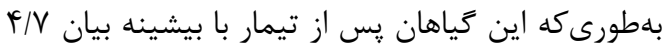

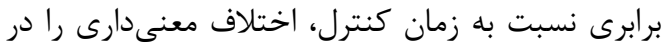

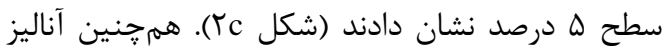

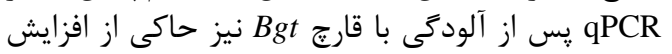

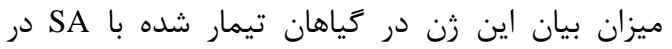

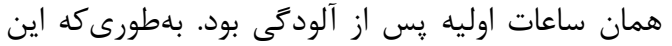

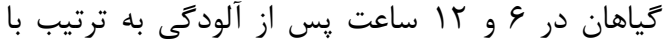

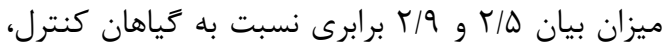

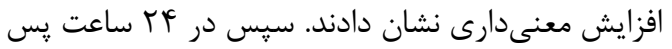

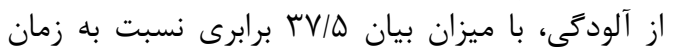

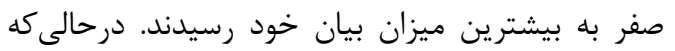

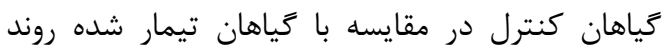

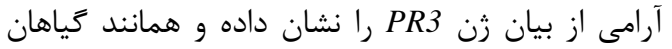

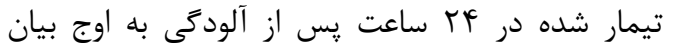

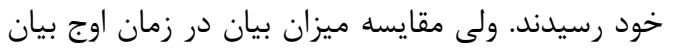

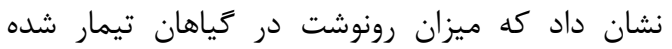

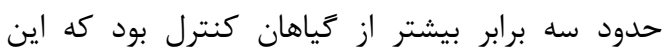

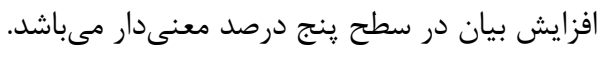

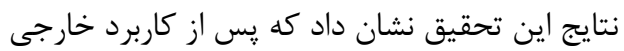

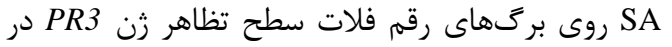

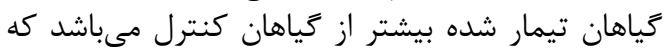

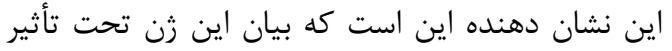

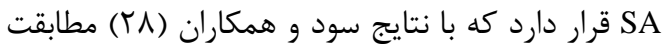

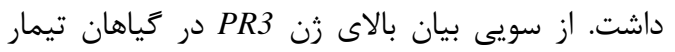

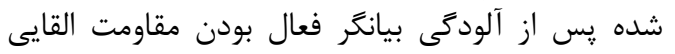

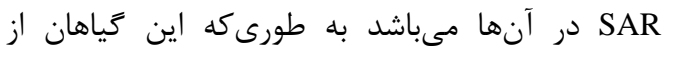

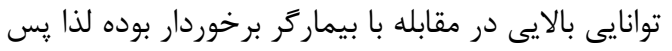

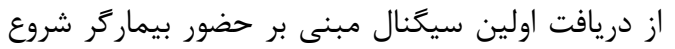
به بيان زنهاى مسير مقاومتى از جمله PR3 مى دمنمايند.

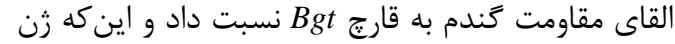

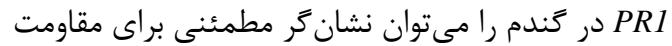

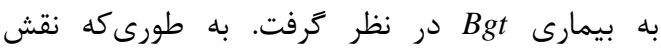

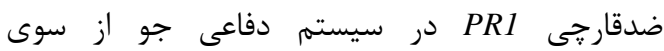

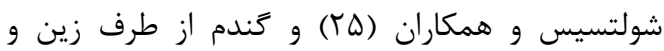

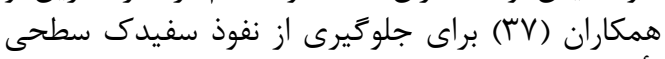

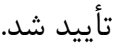

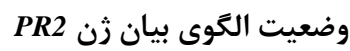

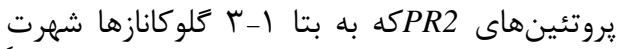

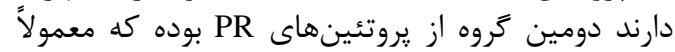

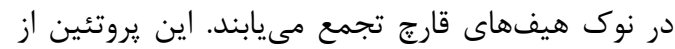

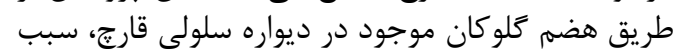

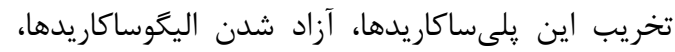

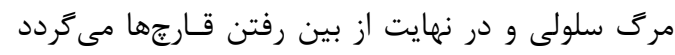

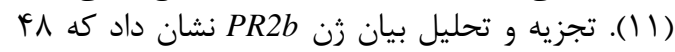

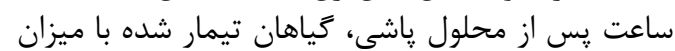

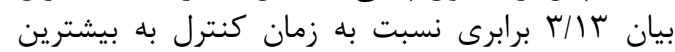

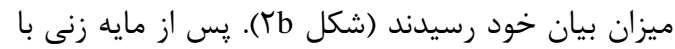
قارج Bgt، نيز ميزان بيان زن رئن

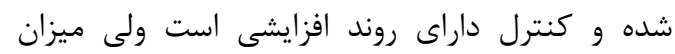

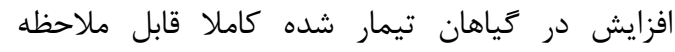

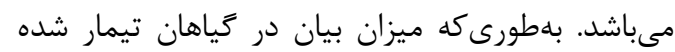

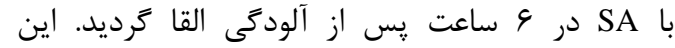

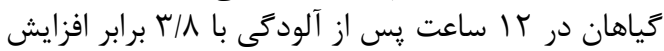

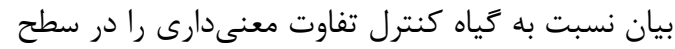

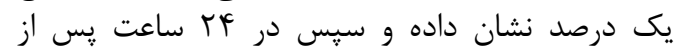

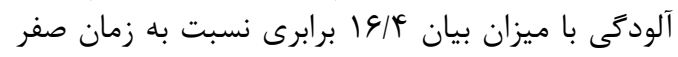

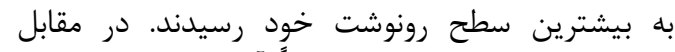

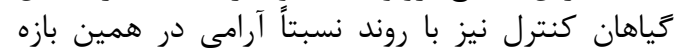

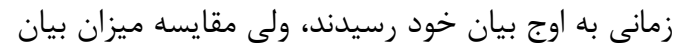

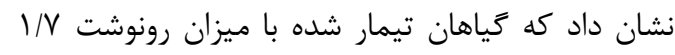

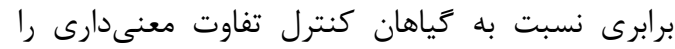
سطح يك درصد نشان دادند.

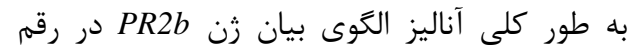

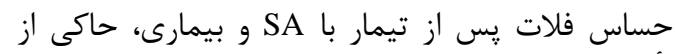

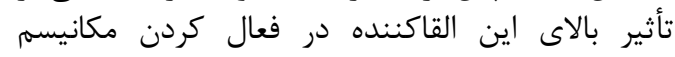

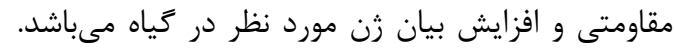

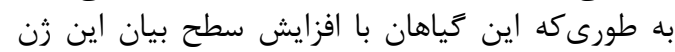

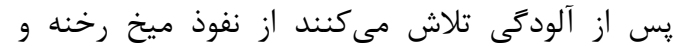

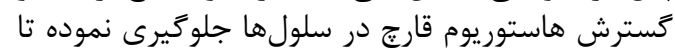

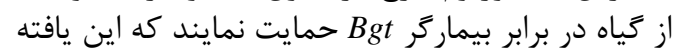

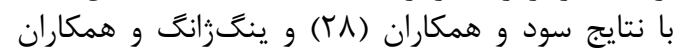

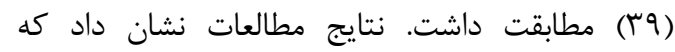

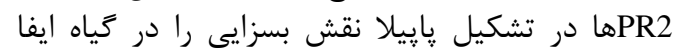

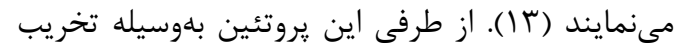
ديواره سلولى قارج سبب آزازئ إسازى اليكوساكاريدها 
PR5 در اين مطالعه نشان داد كه ميزان بيان در كياهان

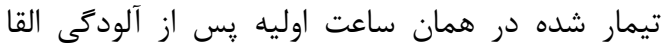

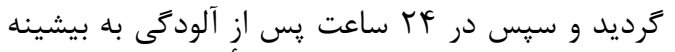

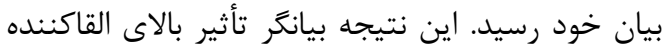

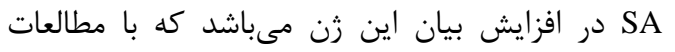

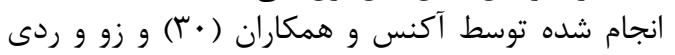

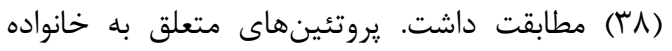

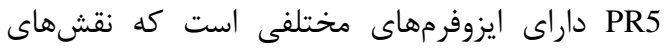

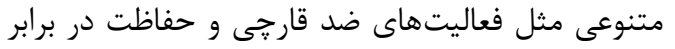

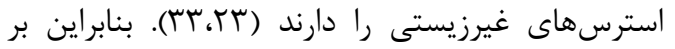

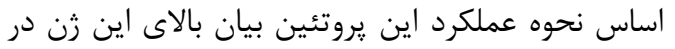

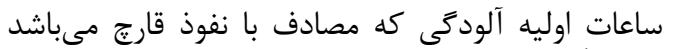

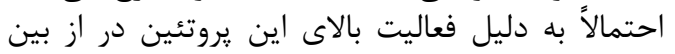

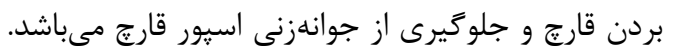

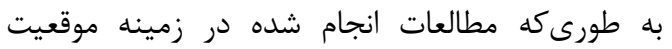

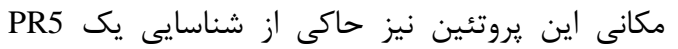
بازى، در ديواره سلولى قارج تئس

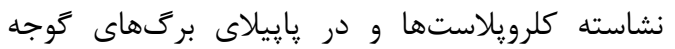

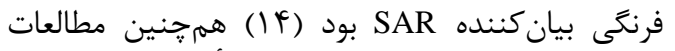

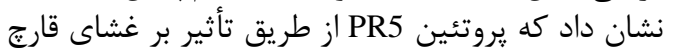

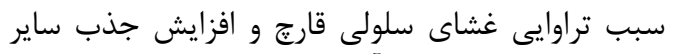
تركيبات ضدقارجى در آنها

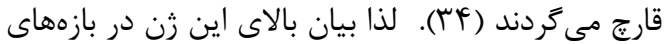

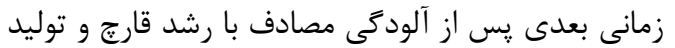

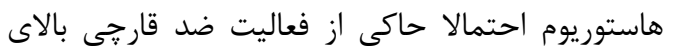

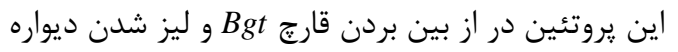

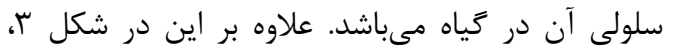

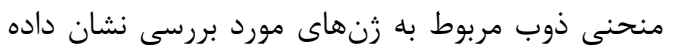

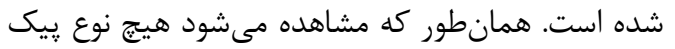

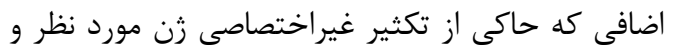

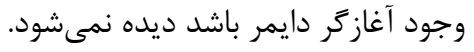

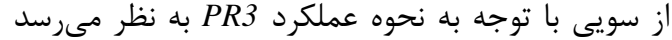

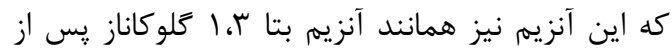

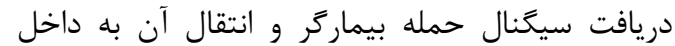

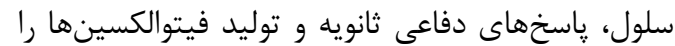

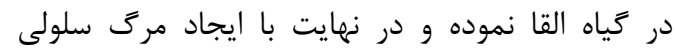

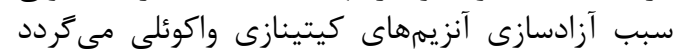

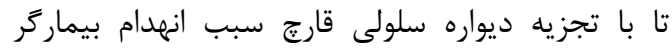

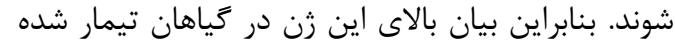

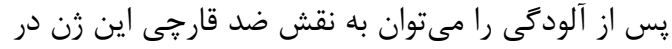

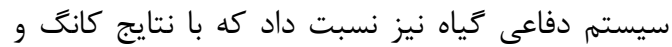

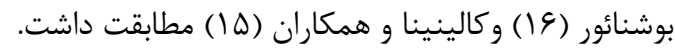

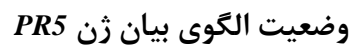
بآناليز الكوى تغييرات زن بئ PR5 نشان دان دادكه ميزان

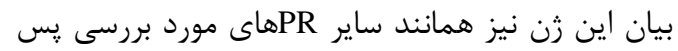

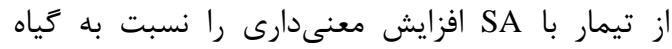

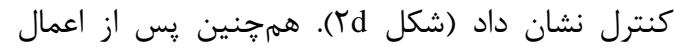

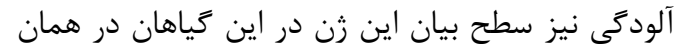

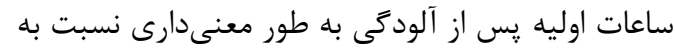

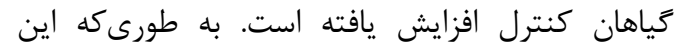

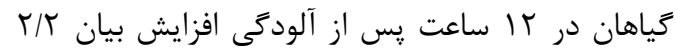

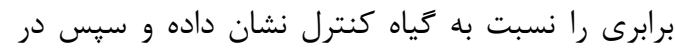

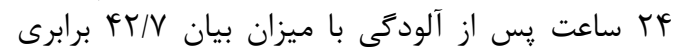

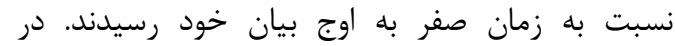

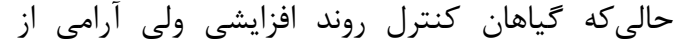

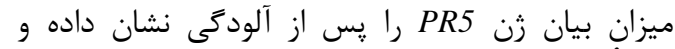

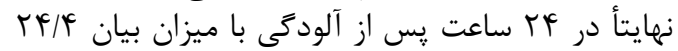

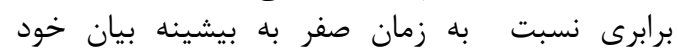

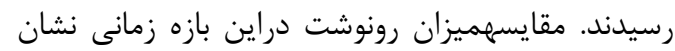

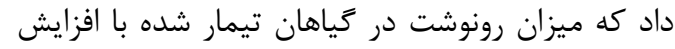

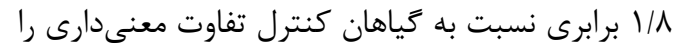

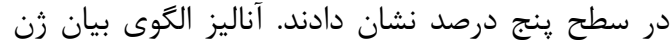


rif بررسى الكوى بيان زن هاى مرتبط با بيمارىزايى در القاى مقاومت به بيمارى سفيدك سطحى در رقم حساس گندم
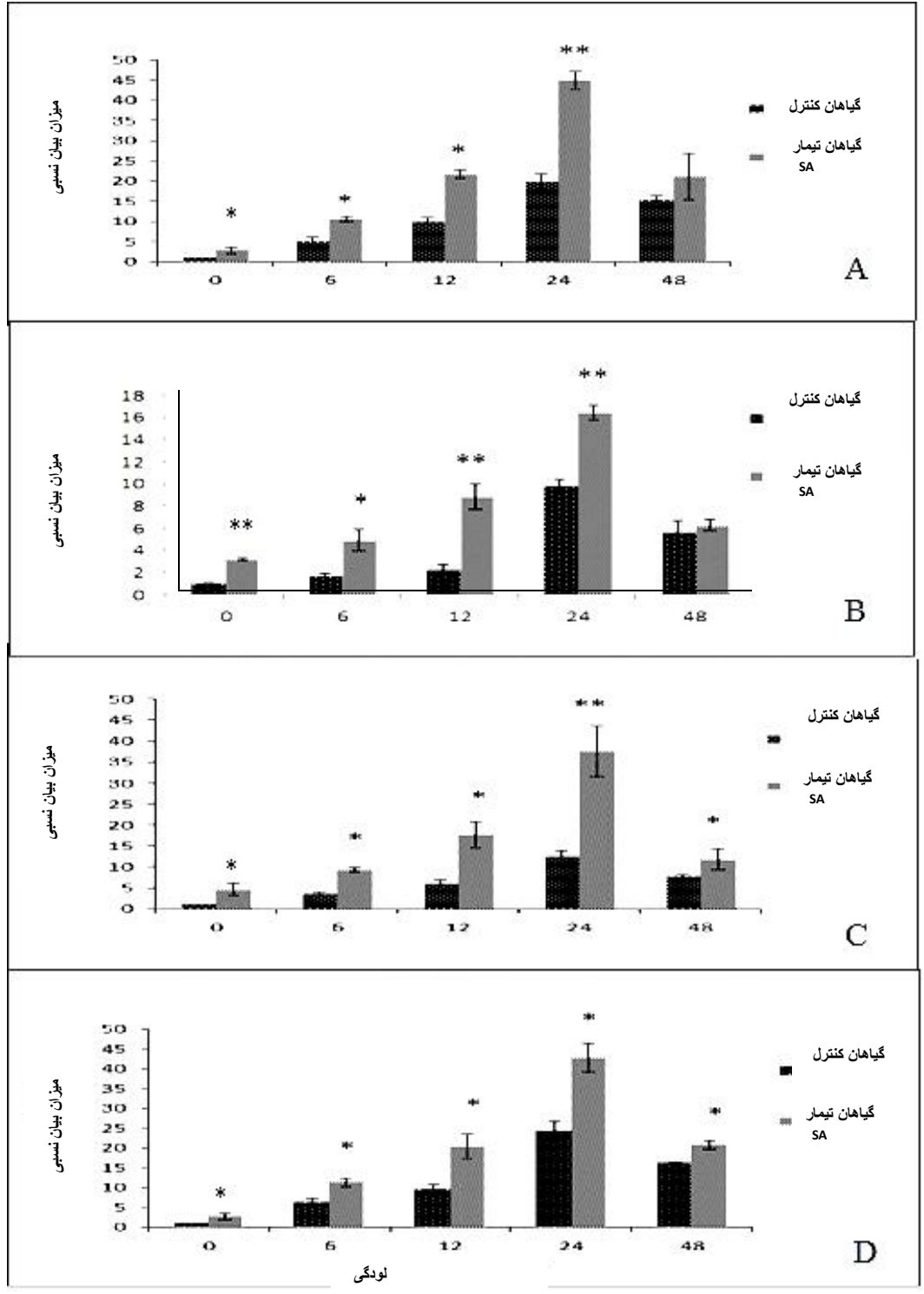

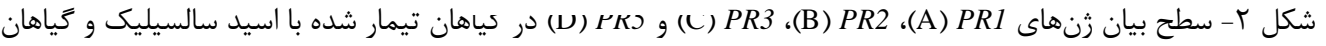

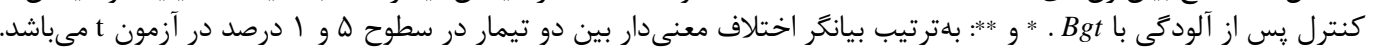

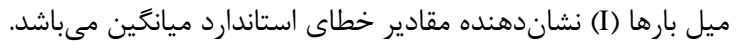



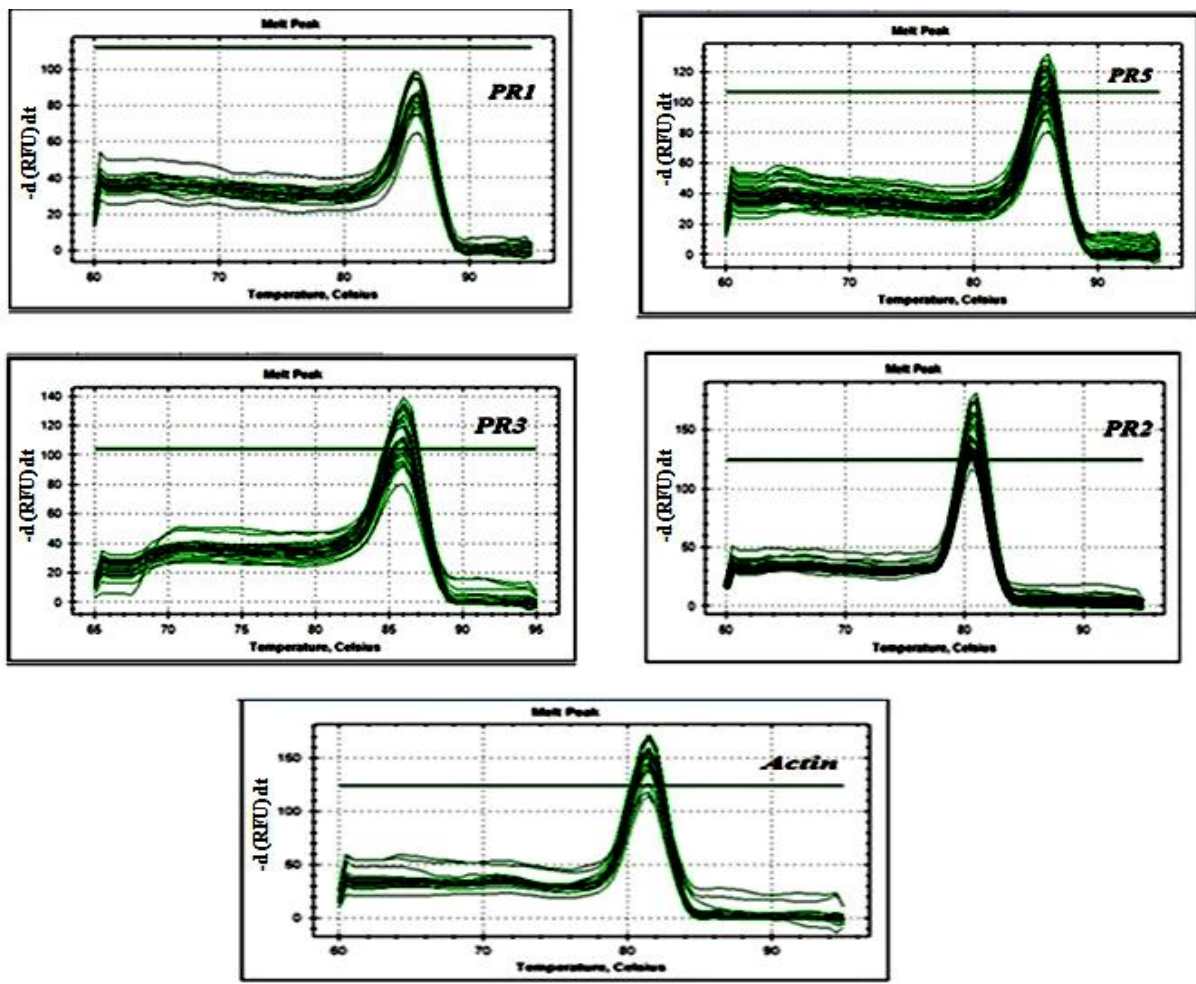

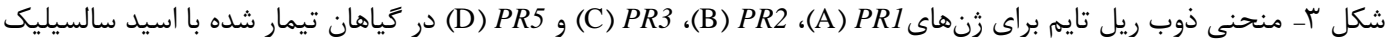

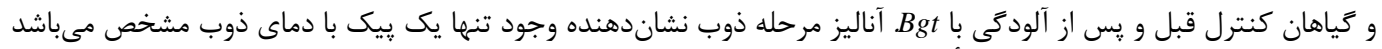

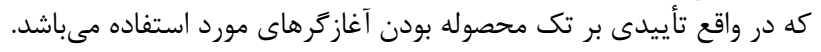

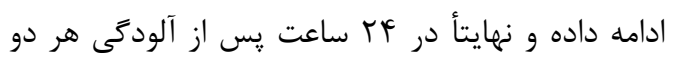

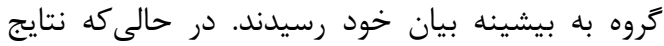

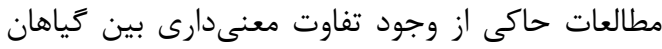

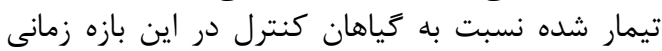

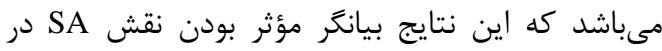

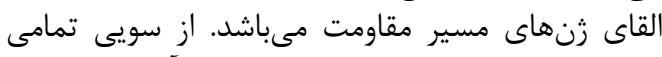

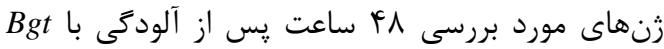

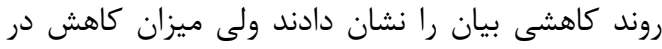

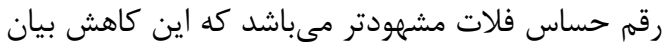

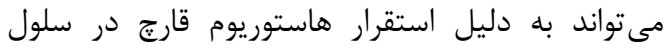

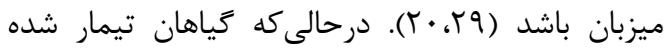

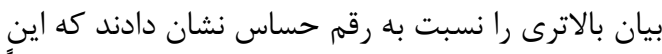

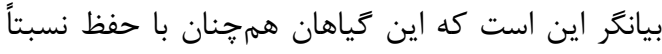

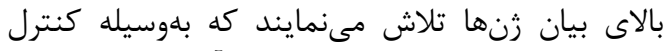

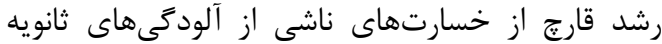
ممانعت نمايند. شواهد همرجنين نشاندهنده اين است كه تركيبات

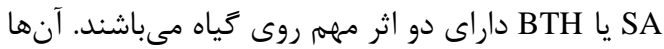

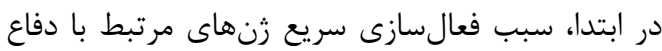

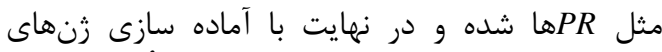
دفاعى سبب تقويت ديواره سلولى و متعاقبأ القاى مرى دائ

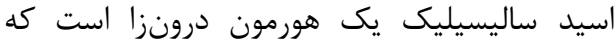

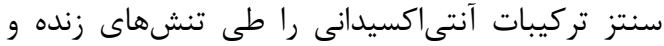

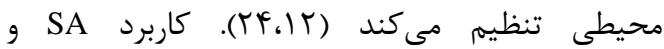

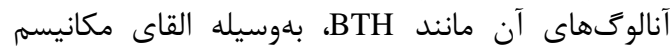

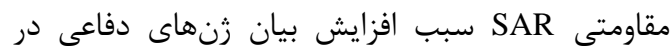

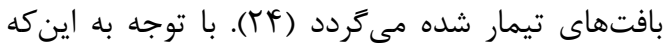

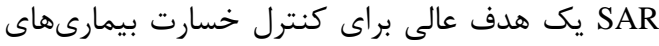

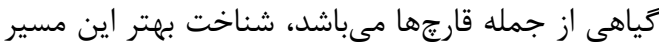

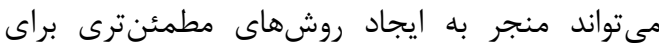

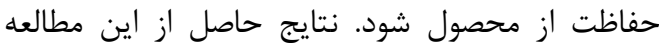

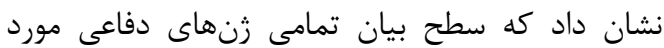

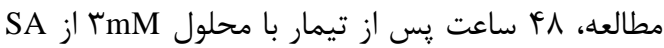

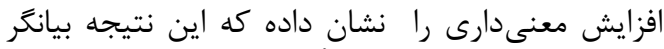

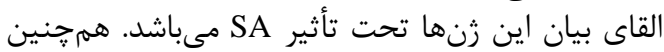

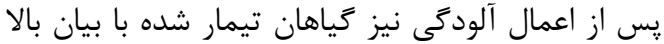

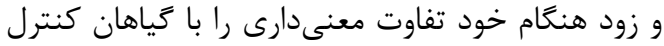

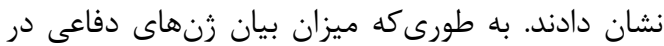

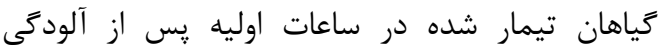

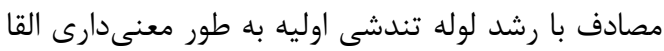

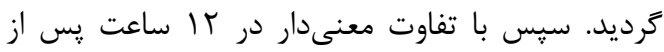

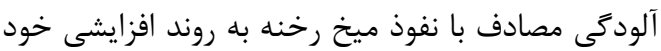


اساس نتايج حاصله بيشنهاد مىشود كه القا كننده

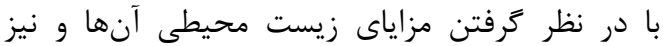

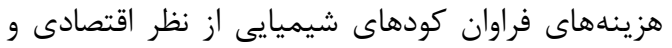

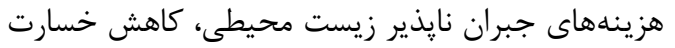

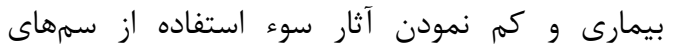

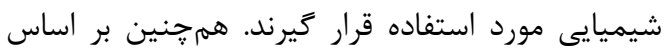

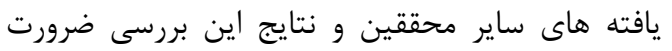

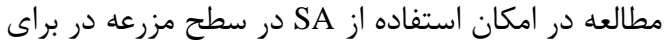

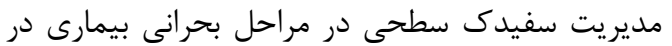

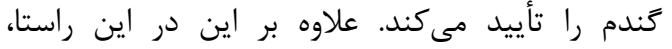

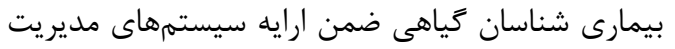

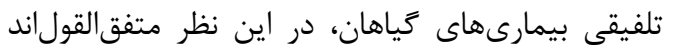

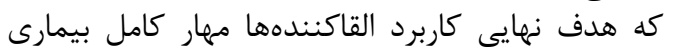

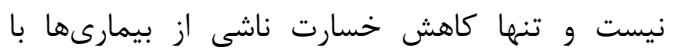

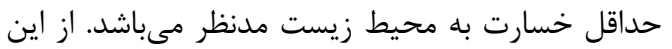

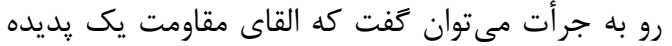

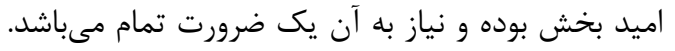

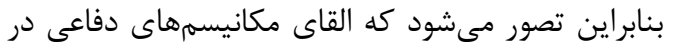

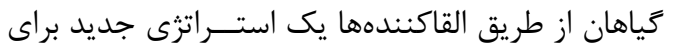

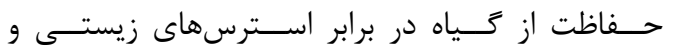

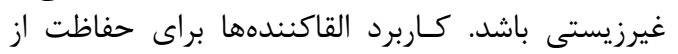

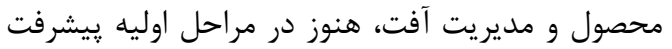

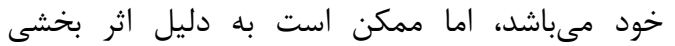

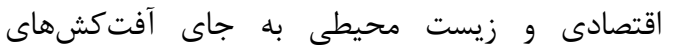
شيميايى رايج مورد استفاده قرار گيرند.
سلولى طى HR در صورت حمله بيمارگر مى مركردند

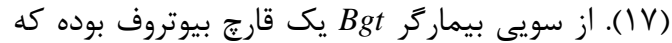

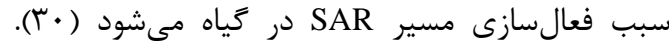

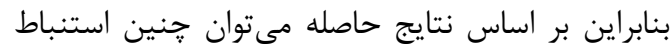

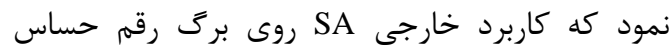

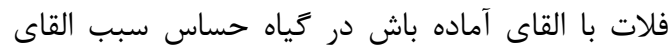

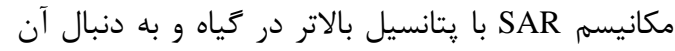

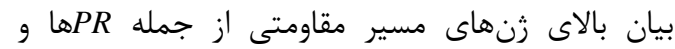

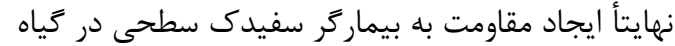

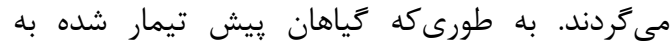

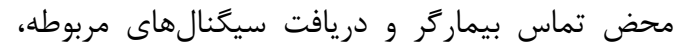

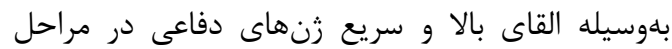

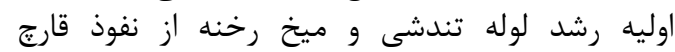

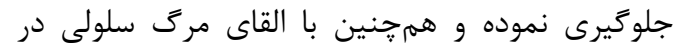

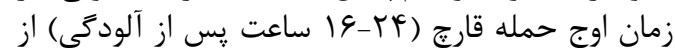

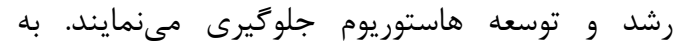

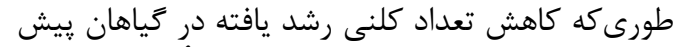

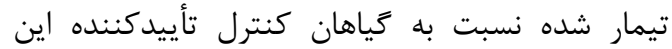
مطلب مىباشد. نتايج حاصله با مطالعات سياندان

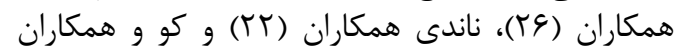

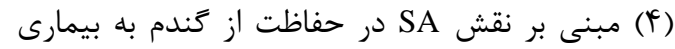
Bgt مطابقت داشت. كلبطور كلى نتايج حاصل از الكَّى بيان زن و و شمارش

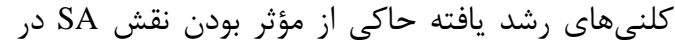
القاى مقاومت در كندم حساس به قارئ مارج

منابع

1. Alkahtani, M., S.A. Omer, M.A. El-Naggar, E.M. Abdel-Kareen and M.A. Mahmoud. 2011. Pathogenesis-rlated protein and phytoalexin induction against Cucumber Powdery Mildew by elicitors. International Journal of Plant Pathology, 2: 63-71.

2. Brodersen, P., F.G. Malinovsky, K. Hématy, M.A. Newman and J. Mundy. 2005. The role of salicylic acid in the induction of cell death in Arabidopsis acd11. Plant Physiology, 138: 1037-45.

3. Buchanan, B.B. 2000. Biochemistry and Molecular Biology of Plants. American Society of Plant Physiologists Rockville, Maryland, pp: 610-628.

4. Cao, J.K., K.F. Zeng and W.B. Jiang. 2006. Enhancement of postharvest disease resistance in Ya Li pear (Pyrus bretschneideri) fruit by salicylic acid sprays on the trees during fruit growth. European Journal Plant Pathology, 114: 363-370.

5. Conner, R.L., A.D. Kuzyk and H. Su. 2003. Impact of powdery mildew on the yield of soft white spring wheat cultivars. Canadian Journal Plant Science, 83: 725-728.

6. Dahleen, L., P.A. Okubara and A.E. Blech. 2001. Transgenic Approaches to Combat Fusarium Head Blight in Wheat and Barley. Crop Science, 41: 628-637.

7. Datta, K., S. Muthukrishnan and S.K. Datta. 1999. Expression and function of PR-proteins genes in transgenic plants. In: Datta, S.K., Pathogenesisrelated proteins in plants. CRC Press, Boca Raton, 261-291.

8. Donofrio, N.M. and T.P. Delaney. 2001. Abnormal callose response phenotype and hypersusceptibility to Peronospora parasitica in defense-compromised Arabidopsis nim 1-1 and salicylate hydroxylase plants Molec. Plant-Microbe Interaction, 14: 439-50.

9. Du, Q., W. Zhu, Z. Zhao, X. Qian and Y. Xu. 2011. Novel benzo-1,2,3-thiadiazole-7-carboxylate derivatives as plant activators and the development of their agricultural applications. Journal of Agricultural and Food Chemistry, 60: 346-353.

10. Glazebrook, J. 1999. Genes controlling expression of defense response in Arabidopsis. Current Opinion Plant Biology, 2: 280-286

11. Hernàndez, H., M. Figueredo, N. Garrido, L. Sànchez and J. Sarracent. 2005. Intranasalimmunisation with a $62 \mathrm{kDa}$ proteinase combined with cholera toxin or $\mathrm{CpG}$ adjuvant protectsagainst Trichomonas vaginalis genital tract infections in mice. International Journal for Parasitology, 35: 1333-1337.

12. Horvath, E., G. Szalai and T. Janda. 2007. Induction of abiotic stress tolerance by salicylic acid signaling. Journal of Plant Growth Regulation, 26: 290-300. 
TIV

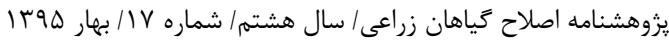

13. Hu, G. and F.H.J. Rijkenberg. 1998. Subcellular localization of $\beta-1,3$-glucanase in Puccinia reconditaf.sp. tritici-infected wheat leaves. Planta, 204: 324-334.

14. Jeun, Y. Ch. and H. Buchenauer. 2001. Infection structures and localization of pathogenesis-related protein AP24 in leaves of tomato plants exhibiting systemic acquired resistance against Phytophthora infestansafter pre-treatment with 3-aminobutyric acid or tobacco necrosis virus. Journal of Phytopathology, 149: 141-153.

15. Kalinina, O., S.L. Zeller and B. Schmid. 2011. Competitive Performance of Transgenic Wheat Resistant to Powdery Mildew. Plos One, 6: 1-11.

16. Kang, Z. and H. Buchenauer. 2002. Immunocytochemical localization of $\beta-1,3$-glucanase and chitinase in Fusarium culmorum-infected wheat spikes. Physiological and molecular plant pathology, 60: 141-153.

17. Kohler, A., S. Schwindling and U. Conrath. 2002. Benzothiadiazole-induced priming for potentiated responses to pathogen infection, wounding, and infiltration of water into leaves requires the NPR 1/NIM1 Gene in Arabidopsis. Plant Physiology. 128: 1046-1056.

18. Linthorst, H.J.M.1991. Pathogenesis-related proteins of plants. Critical Review Plant Science, 10: 123-150.

19. Livak, K.J. and T.D. Schmittgen. 2001. Analysis of relative gene expression data using real Time Quantitative PCR and the $2^{-}$method. Methods, 25: 402-408.

20. Molitor, A., D. Zajic, L.M. Voll, J. Pons-Hückelhoven, B. Samans, K.H. Kogel and F. Waller. 2011. Barley Leaf Transcriptome and Metabolite Analysis Reveals New Aspects of Compatibility and Piriformospora indica-Mediated Systemic Induced Resistance to Powdery Mildew . Molecular PlantMicrobe Interaction, 24: 1427-1439.

21. Muchembled, J., A. Loune`s-Hadj Sahraoui, A. Grandmougin-Ferjani and M. Sancholle. 2006. Changes in lipid composition of Blumeria graminisf. sp. tritici conidia produced on wheat leaves treated with heptanoyl salicylic acid. Phytochemistry, 67: 1104-1109.

22. Nandi, B., K. Kundu, N. Banerjee and S.P.S. Babu. 2003. Salicylic acid induced suppression of Meloidogyne incognitainfestation of okra and cowpea. Nematology, 5: 742-752.

23. Punja, K.Z. 2002. Genetic engineering of plants to enhance resistance to fungal pathogens a review of progress and future prospects. Canadian Journal Plant Pathology, 23: 216-235.

24. Senaranta, T., D. Teuchela, E. Bumm and K. Dixon. 2000. Acetyle salicylic acid (aspirin) and salicylic acid induce multiple stress tolerance in bean and tomato plants. Journal of Plant Growth Regulation, 30: 157-161.

25. Schultheiss, H., C. Dechert, L. Király, J. Fodor, K. Michel, K.H. Kogel and R. Hückelhoven. 2003. Functional assessment of the pathogenesis-related protein PR-1b in barley. Plant Science, 165: 12751280.

26. Siahpoush, S., N. Sahebani and H. Aminian. 2011. Change of some defense compounds of cucumber treated with Bacillus cereusand salicylic acid against Meloidogyne javanica. African Journal of Plant Science, 5: 829-834.

27. Simmons, C.R. 1994. The physiology and molecular biology of plant 1,3-b-d-glucanases and 1,3;1,4b-d-glucanases. Critical Review Plant Science, 13: 325-387.

28. Sood, N., B.S. Sohal and J.S. Lore. 2013. Foliar Application of Benzothiadiazole and Salicylic Acid to Combat Sheath Blight Disease of Rice. Rice Science, 20: 349-355.

29. Spanu, P.D., J.C. Abbott, J. Amselem and T.A. Burgis. 2010. Genome expansion and gene loss in powdery mildew fungi reveal tradeoffs in extreme parasitism. Science, 330: 1543-1546.

30. Uknes, S., B. Mauch-Mani, M. Moyer, S. Potter, S. Williams, S. Dincher, D. Chandler, A. Slusarenko, E. Ward and J. Ryals. 1992. Acquired resistance in Arabidopsis. Plant Cell, 4: 645-656.

31. Van Loon, L.C. and E.A. Van Strien. 1999. The families of pathogenesis-related proteins, their activities, and comparative analysis of PR-1 type proteins. Physiological and Molecular Plant Pathology, 55: 85-97.

32. Van Loon, L.C., M. Rep and C.M.J. Pieterse. 2006. Significance of Inducible Defense-related Proteins in Infected Plants. Phytopathology, 44: 135-162.

33. Velazhahan, R., S.K. Datta and S. Muthukrishnan. 1999. The PR-5 family: thaumatin-like proteins. In: S.K. Datta and S. Muthukrishnan (ed.), Pathogenesis-Related Proteins in Plants. CRC Press, Boca Raton, pp: 107-129.

34. Vigers, A.J., S. Wiedemann, W.K. Roberts, M. Legrand, C.P. Selitrennikoff and B. Fritig. 1992. Thaumatin-like pathogenesisrelated proteins are antifungal. Plant Science, 83:155-161.

35. Vlot, A.C., D.A. Dempsey and D.F. Klessig. 2009. Salicylic acid, a multifaceted hormone to combat disease. Annual Review of Phytopathology, 47: 177-206.

36. Woloshuk, C.P., E.J.S. Meulenhoff, M. Sela-Buurlage, P.J.M. Van den Elzen and B.J.C. Cornelissen. 1991. Pathogen- induced proteins with inhibitory activity toward Phytophthora infestans. Plant Cell, 3: 619-628.

37. Xin, T., X. Wang, H. Peng, Y. Yao, Ch. Xie, Y. Han, Zh. Ni and Q. Sun. 2012. Transcriptome Comparison of Susceptible and Resistant Wheat in Response to Powdery Mildew Infection. Genomics Proteomics Bioinformatics, 10: 94-106.

38. Xu, H. and A.S.N. Reddy. 1997. Cloning and expression of aPR5-like protein from Arabidopsis: inhibition of fungal growth by bacterially expressed protein. Plant Molecular Biology, 34: 949-959.

39. Ying-Zhang, L., Z. Xiao-Hua and T. Hai-Lin. 2003. Increase of $\beta$-1, 3-glucanase and chitinase activities in cotton callus cells treated by salicylic acid and toxin of Verticillium dahliae Kleb. Acta Botanica Sinica, 45: 802-808. 


\title{
Study of $P R$ Gene ExpressionPattern related to in Induced Resistance to Powdery Mildew in Susceptible Wheat Genotype after Treating with Salicylic Acid
}

\author{
Leila Ahangar ${ }^{1}$, Valiollah Babaezad ${ }^{2}$, Gholam Ali Ranjbar ${ }^{3}$, \\ Hamid Najafi Zarrini ${ }^{2}$ and Abbas Biabani ${ }^{4}$ \\ 1- Assistant Professor, Gonbad Kavous University (Corresponding author: 1.ahangar63@gmail.com) \\ 2 and 3- Assistant Professor and Associate Professor, Sari Agricultural Sciences and Natural Resources University \\ 4- Associate Professor, Gonbad Kavous University \\ Received: January 24, $2015 \quad$ Accepted: March 18, 2015
}

\begin{abstract}
Bread wheat is one of the most important food crops which has main position in nutrition of the world's population. The production of this crop were always been faced to a variety of challenges. Powdery mildew, caused by the biotrophic pathogen Blumeria graminis f.sp tritici $(B g t)$, known as a destructive disease of wheat worldwide. There are several methods to control the disease, but use of inducers as of SA, able to induce a systemic resistance in plants are very important. In order to examination the ability of SA for inducing resistance in wheat against $B g t$ fungus, Flat was selected as susceptible cultivar and treated with SA and then exposed to Bgt fungi together with control plants. Then examine the expression rate of $P R 1, P R 2, P R 3$ and $P R 5$ genes using Real Time PCR technique in response to $B g t$ was carried out at 5 time courses and in 3 independent replicates. Results indicated that in both groups of treated and control plants, levels of gene expression were increased after infection for all genes. Maximum expression level of genes were observed at 24 hours after infection. This process was observed slowly in control plants but caused early and faster induction of plant defense genes in treated plants early hours after infection rather than control plant. At 48 hours after inoculation, transcript levels of induced genes started to dampen in both groups of experimental plants, indicating effective suppression of defense associated genes upon haustorium development. Overall, results indicated that SA inducer beacause of able to induce resistance in susceptible cultivar through overexpression of resistance genes and reducing number of colonies grown on Bgt fungus per unit area can one of the candidate of induced resistance in susceptible cultivar.
\end{abstract}

Keywords: Gene Expression, Induction Resistance, Salicylic Acid, Wheat 